\title{
Effect of Acute Umbilical Cord Compression on Hepatic Carbohydrate Metabolism in the Fetal Lamb
}

\author{
COLIN D. RUDOLPH, CHRISTINE ROMAN, AND ABRAHAM M. RUDOLPH \\ Cardiovascular Research Institute and Departments of Pediatrics and Obstetrics, Gynecology and \\ Reproductive Sciences, University of California, San Francisco, California 94143
}

\begin{abstract}
Although the liver plays a central role in glucose homeostasis in the adult, its importance in fetal glucose homeostasis during acute reductions of substrate delivery is unknown. To examine this, we studied eight fetal lambs at $121 \pm 2 \mathrm{~d}$ gestation. We placed catheters in the descending aorta, inferior vena cava umbilical vein and the left $(n=6)$ or right $(n=2)$ hepatic vein, and a balloon occluder around the umbilical cord. At least $4 \mathrm{~d}$ after surgery, before and during umbilical cord compression, we measured blood oxygen saturation, glucose, lactate, and $\mathrm{Hb}$ concentrations, and blood flows using the radiolabeled microsphere technique. Gluconeogenesis was assessed by infusion of $\left[\mathrm{U}^{14} \mathrm{C}\right.$ lactate. Reducing umbilical flow by $50-$ $60 \%$ from a control value of $181 \pm 20 \mathrm{~mL} / \mathrm{min} / \mathrm{kg}$ (mean \pm SD) caused a dramatic decrease in hepatic blood flow from $332 \pm 99$ to $94 \pm 77 \mathrm{~mL} / \mathrm{min} / 100 \mathrm{~g}(p<0.05)$. Oxygen delivery to the fetus fell by $50 \%$ and that to the liver by $73 \%$. However, hepatic $\mathrm{O}_{2}$ consumption was maintained by increased extraction. Glucose delivery to the liver fell from $67 \pm 24$ to $20 \pm 13 \mathrm{mg} / \mathrm{min} / 100 \mathrm{~g}$ ( $p<0.001)$, but lactate delivery did not change. In spite of the maintenance of lactate delivery, net hepatic lactate uptake fell significantly from $3.3 \pm 1.7$ to $1.4 \pm 0.9 \mathrm{mg} / \mathrm{min} 100 \mathrm{~g}(p<0.05)$. This could account, in part, for the increase of blood lactate concentration from $16 \pm 4$ to $27 \pm 7 \mathrm{mg} / \mathrm{dl}$. Although hepatic glucose delivery fell markedly, net glucose production by the liver increased from $0.1 \pm 2.4$ to $3.9 \pm 7.3 \mathrm{mg} /$ $\min / \mathbf{1 0 0} \mathrm{g}(p<0.05)$. Presumably, this glucose production is from glycogenolysis because no hepatic gluconeogenesis from labeled lactate could be detected. During umbilical cord compression, hepatic glycogenolysis contributed 1.5 $\pm 2.8 \mathrm{mg} / \mathrm{min} / \mathrm{kg}(30 \%)$ of total glucose utilized by the fetus. The mechanisms responsible for fetal hepatic glycogenolysis are yet to be delineated. (Pediatr Res 25:228233,1989 )
\end{abstract}

\section{Abbreviations}

\author{
$\dot{\mathrm{Q}}$, blood flow/min \\ $\dot{\mathrm{V}}, \mathrm{flux} / \mathrm{min}$ \\ DA, descending aorta \\ RHV, right hepatic vein \\ LHV, left hepatic vein \\ $P V$, portal vein \\ $\mathrm{RL}$, right lobe of the liver \\ LL, left lobe of the liver
}

Received February 16, 1988; accepted October 26, 1988

Correspondence: Colin D. Rudolph M.D. Ph.D., 1403 HSE, Box 0544, University of California, San Francisco, San Francisco, CA 94143.

Supported by United States Public Health Service Program Project Grant HL24056.
UV, umbilical vein

$\mathrm{C}_{\text {(substrate)RHV }}$, concentraton of substrate in right hepatic vein QUV, total umbilical venous blood flow

QUV liver, blood flow to the liver from the umbilical vein

$\dot{\mathbf{V}}_{\text {(substrate) }}$, substrate flux across the liver

Acute umbilical cord compression, which causes hypoxemia and acidemia, is one of the most common causes of fetal distress. The homeostatic mechanisms invoked by the fetus to supply adequate oxygen to the brain and heart have been well characterized (1). As placental blood flow decreases, regional blood flows alter to maintain brain and heart flow. An increased proportion of the oxygen-rich blood from the UV is shunted away from the liver through the ductus venosus to the brain and heart, with blood flow and oxygen delivery to the liver decreasing by $50--75 \%$.

Changes in fetal substrate delivery and utilization have not been studied during umbilical cord compression. In the unstressed fetal lamb, $40 \%$ of the energy substrates to the fetus are provided by glucose and $20 \%$ by lactate (2). Glycogen is synthesized by the liver (3), but no gluconeogenesis or glycogenolysis occurs (4). We have demonstrated that during hypoxemia the fetal liver produces glucose, but we did not determine whether this results from glycogenolysis or gluconeogenesis. Although gluconeogenesis from lactate occurs shortly after birth fetal gluconeogenesis does not occur after administration of epinephrine or glucagon, or during ventilation and oxygenation $(5,6)$. The primary aim of our studies was to investigate glucose and lactate metabolism after acute umbilical cord compression in the fetal lamb. As the liver appears to play an important role in fetal intermediary metabolism, utilizing up to $90 \%$ of the lactate delivered to the unstressed fetus (7) and providing glucose during hypoxic stress (8), we focused on the changes in hepatic glucose and lactate metabolism. In addition, we reasoned that reduced or absent umbilical flow may be the important birth-associated change that stimulates hepatic gluconeogenesis; therefore, we measured the hepatic production of glucose from labeled lactate after umbilical cord compression.

\section{MATERIALS AND METHODS}

Animal preparation. Studies were performed on eight fetal lambs aged 120-124 d of gestation at the time of surgical preparation (term, $147 \mathrm{~d}$ ). The ewes were fasted for $24 \mathrm{~h}$ before surgery. Epidural anesthesia was achieved with $2 \mathrm{ml}$ of $1 \%$ tetracaine hydrochloride, and ketamine for sedation was given intravenously in doses of $100 \mathrm{mg}$ every 10 to $15 \mathrm{~min}$. Local 
anesthesia with $0.25 \%$ lidocaine hydrochloride was used for all fetal incisions. A continuous infusion of $10 \%$ dextrose $0.9 \%$ $\mathrm{NaCl}$ was given to the ewe throughout the surgical procedure.

Polyvinyl catheters were inserted into a maternal pedal artery and vein and advanced to the DA and inferior vena cava, respectively. In the fetus, polyvinyl catheters were inserted into the DA, inferior vena cava, UV and LHV $(n=6)$ or RHV $(n=$ 2) by methods described previously (9). Briefly, a 3- to 4-cm incision was made in the uterine horn over a fetal hind limb, and catheters were inserted into both fetal pedal arteries and veins and advanced to the DA and inferior vena cava, respectively. The amnion was then separated from the allantoic membrane to expose a large umbilical vein along the mesenteric border of the uterus. A $3.5 \mathrm{~F}$ multiple-side hole catheter was introduced into a small tributary entering the vein and was advanced $12-15 \mathrm{~cm}$ into one of the major UV. An amniotic catheter was inserted, and the uterine incision was sutured. The uterus was extracted further to expose the right chest of the fetus, and a second uterine incision was made. A right thoracotomy was performed through the eighth intercostal space, and the lung was retracted, exposing the inferior vena cava and diaphragm. The inferior vena cava was punctured through a purse-string suture just caudal to the entry of the diaphragmatic vein; a catheter was then advanced into the hepatic vein. The catheter position was verified at surgery by comparing the oxygen saturation in the hepatic vein with that in the UV (9). The fetal incision was sutured, and a silicone rubber cuff with an inflatable balloon was placed around the proximal portion of the umbilical cord (10). Before closure of the uterine incision, amniotic fluid was replaced with warm $0.9 \% \mathrm{NAC} 1$ solution. All catheters were tunneled through the skin to the ewe's flank. Catheter positions ultimately were verified by post mortem examination. After surgery, the ewes recovered at least $4 \mathrm{~d}$ before study; they were fed a standard diet of alfalfa pellets. All vascular catheters were flushed daily with heparin solution $(1 \mathrm{mg} / \mathrm{mL})$. Antibiotics (penicillin, $1000000 \mathrm{U}$, and kanamycin, $400 \mathrm{mg}$ ) were administered intravenously to the ewe and were instilled into the amniotic cavity daily.

Experimental protocol. On the day of the study, the ewe was placed in a metabolic study cage and allowed access to alfalfa pellets and water. A bolus of $40 \mu \mathrm{Ci} /$ liter[U- $\left.{ }^{14} \mathrm{C}\right]$ lactate (New England Nuclear; $150-170 \mathrm{mCi} / \mathrm{mmol}$ ) was injected into the fetal inferior vena cava. The bolus was followed by an infusion of ${ }^{14} \mathrm{C}$ lactate $(30 \mu \mathrm{Ci} / \mathrm{h})$ achieving a substrate radioactivity of at least $>600 \mathrm{dpm} / \mathrm{mL}$ (four times background) in the undiluted blood samples. This radioactivity was attained within $30 \mathrm{~min}$ after injection.

At 30 min after the ${ }^{14} \mathrm{C}$-lactate bolus, control blood samples were taken from the maternal arterial and fetal descending aortic, hepatic venous, and umbilical venous catheters for measurements of blood $\mathrm{Hb}$ concentration, percentage of $\mathrm{O}_{2}$ saturation, and glucose and lactate concentrations. In studies in which a right hepatic venous catheter was inserted, samples were also obtained from the inferior vena cava. Maternal and fetal descending aortic blood gases and $\mathrm{pH}$ were also measured. To assess hepatic gluconeogenesis from lactate, $1 \mathrm{~mL}$ blood samples were obtained from the hepatic vein and UV and were analyzed for ${ }^{14} \mathrm{C}$ glucose and ${ }^{14} \mathrm{C}$ lactate concentrations. Radiolabeled microspheres were then injected into the umbilical venous catheter while a reference sample was withdrawn from the fetal DA at 3 $\mathrm{mL} / \mathrm{min}$, allowing measurement of the distribution of umbilical venous blood flow and calculation of hepatic blood flow as previously described (8). All blood withdrawn from the fetus was immediately replaced with donor fetal blood or, if this was not available, with maternal blood.

After control measurements were obtained, the umbilical cord was compressed by inflating the balloon occluder. In a departure from the procedure of previously reported studies in our laboratory (1), an electromagnetic flow transducer was not placed around the common umbilical artery; therefore, reductions in umbilical flow could not be directly monitored. Instead, we monitored the fetal descending aortic $\mathrm{Hb}$ saturation and inflated the balloon occluder to decrease saturations by $50 \%$ of control values. Blood samples were collected and microsphere injections were made $15 \mathrm{~min}$ and $30 \mathrm{~min}$ after initially achieving this reduction in oxygen saturation. After 15 min of cord compression, umbilical flow, as measured subsequently by microsphere, was found to be reduced to $50 \%$ of the control flow rates. However, during the period of continued cord compression from 15 to $30 \mathrm{~min}$, there was a further reduction in oxygen saturation in the descending aorta to $35 \%$ of control values and in umbilical blood flow to $45 \%$ of control flow rates. Changes in descending aortic oxygen saturation were proportional to reductions in umbilical flow $(r=0.73, p<0.001)$. At the end of studies, the sheep were killed using pentobarbital intravenously, and $10 \mathrm{ml}$ of saturated $\mathrm{KCl}$ were injected intravenously. The placenta and fetus were removed for dissection and measurement of microsphere distribution. Catheter positions were confirmed.

Measurements. Blood gases and $\mathrm{pH}$ were determined on a Corning model 175 blood gas analyzer (Corning Glass Works, Medfield, MA). Blood $\mathrm{Hb}$ concentrations and $\mathrm{Hb}$ oxygen saturation were measured in duplicate on a Radiometer hemoximeter (model OSM2). Blood $\mathrm{O}_{2}$ content was calculated as the product of $\mathrm{O}_{2}$ saturation, $\mathrm{Hb}$ concentration, and an $\mathrm{Hb} \mathrm{O}_{2}$ binding capacity of $1.35 \mathrm{~mL} / \mathrm{g} \mathrm{Hb}$. Blood glucose and lactate were measured in duplicate by enzymatic methods (Sigma Chemical Co., St. Louis, MO; reproducibility of measurements is within $2 \%$ in our laboratory.

${ }^{14} \mathrm{C}$-lactate radioactivity was measured using the method of Rognstad and Katz (11), described by Sparks et al. $(12) .{ }^{14} \mathrm{C}-$ glucose radioactivity was measured using the radiochemical method described by Hay et al. (4).

Blood flows were measured by the microsphere method (13). Microspheres of $15 \mu$ diameter, labeled with ${ }^{52} \mathrm{Cr},{ }^{57} \mathrm{Co},{ }^{114} \mathrm{In}$, ${ }^{65} \mathrm{Zn},{ }^{54} \mathrm{Mn},{ }^{95} \mathrm{Nb},{ }^{153} \mathrm{Gd},{ }^{85} \mathrm{Sr}$, or ${ }^{113} \mathrm{Sn}$, were injected into the UV while a reference sample was obtained from the DA. Liver blood flow, portal venous blood flow, and umbilical venous blood flow were calculated as described below. As a reference sample was obtained only from the DA, blood flows were otherwise determined only for adrenals, kidneys, and lower carcass.

Calculations. Previous studies in our laboratory have defined blood supply to the RL and LL (14). The RL receives almost all of the portal venous blood as well as a contribution from the UV. Portal venous flow consistently is distributed only to the $\mathrm{RL}$, so determination of portal venous distribution usually is not required. The left lobe receives only umbilical venous blood. The contribution from the hepatic artery to both lobes is negligible even after partial umbilical cord compression (1). In three fetuses, we studied changes in the hepatic arterial contribution to total liver blood flow after 15 and $30 \mathrm{~min}$ of cord compression. The hepatic arterial contribution never exceeded $5.8 \%$ of total liver blood flow (Rudolph CD, Roman C, Rudolph AM, unpublished observation). Therefore, using a single umbilical venous injection, fetal organ flows, liver flows, and percentage of umbilical flow shunted through the ductus venosus can be calculated as:

$$
\begin{aligned}
& \dot{\mathrm{Q}}_{U V_{\text {(liver) }}}=\left[\mathrm{dpm}_{\text {(liver) }} / \mathrm{dpm}_{\text {(total body) }}\right] \times \dot{\mathrm{Q}}_{\text {placenta }} \\
& \dot{\mathrm{Q}}_{P V_{\text {(liver) }}}=\mathrm{Q}_{\text {spleen }}+\dot{\mathrm{Q}}_{\text {rumen, stomach, gut, pancreas }} \\
& \% \mathrm{Q}_{U V_{\text {(liver) }}}=\mathrm{dpm}_{\text {(liver) }} / \mathrm{dpm}_{\text {(total body) }} \\
& \% \dot{\mathrm{Q}}_{U V_{\text {(ductus venosus) }}}=100-\% \dot{\mathrm{Q}}_{U V_{\text {(liver) }}} \\
& \dot{\mathrm{Q}}_{\text {placenta or organs }}=\dot{\mathrm{Q}}_{\text {reference }} \times[\mathrm{dpm} \text { placenta or organ } \\
& \text { sample }
\end{aligned}
$$

where: $\mathrm{dpm}=$ disintegration/min of isotope injected, $\dot{\mathrm{Q}}_{U_{\text {V(liver })}}=$ flow to liver or liver lobe from the UV. Using this approach, the variation in flow measurements between paired injections has previously been demonstrated to be less than $10 \%$ (1). Organ flows are expressed as $\mathrm{mL} / \mathrm{min} / 100 \mathrm{~g}$.

Oxygen, glucose, lactate, and ${ }^{14} \mathrm{C}$-substrates perfusing the $\mathrm{LL}$ and RL were calculated as previously described (14). Substrate or $\mathrm{O}_{2}$ flux across the LL requires measurement of LHV and UV 
substrate concentrations:

$$
\dot{\mathrm{V}}_{\text {(substrate)LL }}=\dot{\mathrm{Q}}_{\left(U \eta_{L L}\right.} \times\left[\mathrm{C}_{\text {substrate)UV }}-\mathrm{C}_{(\text {substrate)LHV }}\right]
$$

whereas substrate flux across the RL requires the measurement of substrate concentration using the $\mathrm{PV}$ or inferior vena cava and RHV:

$$
\dot{\mathrm{V}}_{(\text {substrate }) R L}=\left[\dot{\mathrm{Q}}_{U \eta_{R L}}+\dot{\mathrm{Q}}_{(P V)}\right] \times\left[\mathrm{C}_{(\text {substrate) } \mathrm{PV}}-\mathrm{C}_{(\text {substrate)RHV }}\right] .
$$

To determine whether lactate was utilized for hepatic gluconeogenesis, the flux of labeled glucose across the liver was calculated using the formulas for substrate flux, substituting $\mathrm{cpm}_{\text {glucose }}$ for substrate concentration. Dividing this value by the $\mathrm{sp}$ act of lactate entering the liver provides a measure of the rate at which lactate is converted to glucose/min $(15,17)$.

Conversion of lactate to glucose $=\left[\left(\mathrm{dpm}_{\text {glucose }}\right.\right.$ leaving liver $)-$ ( $\mathrm{dpm}_{\text {glucose }}$ entering liver)]/sp act of lactate entering liver.

The net substrate uptake or production by the total liver was calculated by assuming that the flux across both lobes was identical:

$$
\dot{\mathrm{V}}_{\text {(substrate) }} \text { Total liver }=\dot{\mathrm{V}}_{\text {substrate (LL or RL) }} \times[\text { Liver } \mathrm{w}(\mathrm{g}) / 100] .
$$

Placental flux of oxygen and substrates was calculated as:

$$
\dot{\mathrm{V}}_{\text {placenta }}=\dot{\mathrm{Q} U V} \times\left[\mathrm{C}_{\text {(substrate)DA}}-\mathrm{C}_{\text {(substrate)UV }}\right] \times(\mathrm{DA}-\mathrm{UV}
$$
substrate concentrations).

Statistical analysis. The data, expressed as the mean $\pm \mathrm{SD}$, were analyzed using a computerized statistical program (Statview $512+)$. Because, qualitatively, results were similar whether the RHV or LHV were cannulated, data were pooled for analysis. ANOVA for repeated measures or, if appropriate, Friedman's nonparametric analysis of repeated measures was used to compare the control values to values after partial cord compression. Multiple comparison testing was performed only if the ANOVA testing first rejected a multisample hypothesis of equal means with $p<0.05$. Differences from control were then analyzed using Dunnett's multiple comparison test. Correlation between physiologic variables was tested using least squares polynomial regression analysis with selection of the highest degree polynomial that yielded statistically significant coefficients for the relation between variables; $p<0.05$ was considered statistically significant.

\section{RESULTS}

Changes in blood pressure, heart rate, $\mathrm{Hb}$ concentration, blood gases, and $\mathrm{pH}$, and lower body organ blood flows after 15 and $30 \mathrm{~min}$ of acute umbilical cord compression closely paralleled results previously obtained in our laboratory after $5 \mathrm{~min}$ of cord compression $(10,16)$. During cord compression, umbilical blood flow decreased from $181 \pm 20 \mathrm{~mL} / \mathrm{min} / \mathrm{kg}$ to $89 \pm 20$ after 15 $\min (50 \%$ reduction, $p<0.001)$ and $79 \pm 32$ after $30 \min (55 \%$ reduction, $p<0.001$ versus control but not significantly different from $15 \mathrm{~min}$ flow). The percentage of umbilical flow shunted away from the liver through the ductus venosus to the fetal body increased from $42 \pm 5$ to $58 \pm 5(p<0.05)$ and $67 \pm 5 \%(p<$ 0.05 ) after 15 and $30 \mathrm{~min}$ of cord compression, respectively. Liver blood flow decreased significantly from $332 \pm 99$ to $142 \pm$ $67(p<0.05)$ and $94 \pm 77 \mathrm{~mL} / \mathrm{min} / 100 \mathrm{~g}(p<0.05)$. Previously, after $5 \mathrm{~min}$ of cord compression, we noted a small increase in lower carcass flow; however, with the more prolonged compression in these studies, lower carcass flow fell from control values of $23 \pm 13$ to $17 \pm 5$ and $16 \pm 8 \mathrm{~mL} / \mathrm{min} / 100 \mathrm{~g}(p<0.05)$ after 15 and $30 \mathrm{~min}$ of cord compression, respectively.

Fetal heart rate decreased for the first 5-10 min of cord compression, but after 15 and $30 \mathrm{~min}$ was not different from control rates of $160 \pm 27$ beats/min. Blood pressure in the DA was also unchanged from control values of $68 \pm 14$ torr systolic and $41 \pm 9$ diastolic. Blood $\mathrm{pH}$ decreased progressively during cord compression from control values of $7.37 \pm 0.04$ to $7.31 \pm$ $0.6(p<0.001)$ after $15 \mathrm{~min}$ and $7.27 \pm 0.2(p<0.001)$ after 30 min. Blood $\mathrm{P}_{\mathrm{CO}_{2}}$ increased from controls of $54 \pm 7$ torr to $59 \pm$ 5 and $65 \pm 7<0.001)$, and blood $\mathrm{P}_{\mathrm{O}_{2}}$ decreased from $23 \pm 3$ torr to $17 \pm 3$ and $15 \pm 1(p<0.001)$ after 15 and 30 min of cord compression, respectively. $\mathrm{HB}$ concentration increased from $9.54 \pm 1.5$ to $10.65 \pm 1.8 \mathrm{~g} / \mathrm{dL}(p<0.001)$.

Changes in oxygen, glucose, and lactate concentrations in the DA, UV, and hepatic vein and in the umbilical-placental arteriovenous gradient are shown in Table 1. Changes in oxygen, glucose, and lactate delivery to the fetus and umbilical uptake after acute cord compression are shown in Table 2 . Umbilicalplacental delivery of oxygen to the fetus decreased from $19.5 \pm$ 5.2 to $9.5 \pm 3.1 \mathrm{~mL} / \mathrm{min} / \mathrm{kg}(p<0.001)$ after $30 \mathrm{~min}$ of cord

Table 1. Effect of acute cord compression on oxygen, glucose, and lactate concentrations in DA and umbilical and hepatic veins and on umbilical placental arteriovenous concentration differences in eight fetal lambs*

\begin{tabular}{lccc}
\hline & \multicolumn{3}{c}{ Cord compression } \\
\cline { 2 - 4 } & Control & $15 \mathrm{~min}$ & $30 \mathrm{~min}$ \\
\hline $\mathrm{O}_{2}$ content $(\mathrm{mL} / \mathrm{dL})$ & & & \\
$\mathrm{DA}$ & $7.2 \pm 2.4$ & $5.1 \pm 2.2 \dagger$ & $3.8 \pm 0.7 \dagger$ \\
UV & $11.0 \pm 2.5$ & $11.0 \pm 2.2$ & $11.3 \pm 2.4$ \\
Hepatic vein & $9.6 \pm 2.7$ & $7.9 \pm 2.3 \ddagger$ & $6.0 \pm 1.8 \S$ \\
Placental arteriovenous & $3.6 \pm 0.5$ & $5.8 \pm 1.0 \S$ & $7.5 \pm 1.9 \dagger$ \\
$\quad$ difference & & & \\
& & & \\
Glucose (mg/dL) & & & \\
DA & $16.5 \pm 4.3$ & $15.8 \pm 5.4$ & $15.5 \pm 4.1$ \\
UV & $18.4 \pm 4.5$ & $19.5 \pm 5.4$ & $20.3 \pm 5.5$ \\
Hepatic vein & $18.3 \pm 4.7$ & $19.8 \pm 5.2$ & $23.2 \pm 6.5 \S$ \\
Placental arteriovenous & $1.9 \pm 0.7$ & $3.6 \pm 1.4$ & $4.7 \pm 2.6 \S$ \\
difference & & & \\
Lactate (mg/dL) & & & \\
DA & $16.2 \pm 4.4$ & $20.8 \pm 6.1 \ddagger$ & $27.1 \pm 6.8 \dagger$ \\
UV & $17.3 \pm 4.5$ & $22.4 \pm 6.5 \dagger$ & $28.5 \pm 7.0 \dagger$ \\
Hepatic vein & $16.3 \pm 4.2$ & $21.0 \pm 6.6 \S$ & $25.8 \pm 5.5 \S$ \\
Placental arteriovenous & $1.1 \pm 0.5$ & $1.6 \pm 0.7$ & $1.4 \pm 1.4$ \\
difference & & & \\
\hline
\end{tabular}

* Placental arteriovenous concentration difference is calculated by subtracting descending aortic from umbilical venous $\mathrm{O}_{2}$ or substrate content.

$\dagger p<0.001$

$\ddagger p<0.05$.

$\S p<0.01$.

\begin{tabular}{|c|c|c|c|}
\hline & \multicolumn{3}{|c|}{ Cord compression } \\
\hline & Control & $15 \mathrm{~min}$ & $30 \mathrm{~min}$ \\
\hline $\begin{array}{l}\mathrm{O}_{2} \text { delivery to fetus } \\
(\mathrm{mL} / \mathrm{min} / \mathrm{kg})\end{array}$ & $19.5 \pm 5.2$ & $9.6 \pm 2.9^{*}$ & $9.5 \pm 3.1^{*}$ \\
\hline Umbilical $\mathrm{O}_{2}$ uptake & $6.51 \pm 1.2$ & $5.2 \pm 1.3$ & $6.2 \pm 2.1$ \\
\hline $\begin{array}{l}\text { Glucose delivery to fetus } \\
(\mathrm{mg} / \mathrm{min} / \mathrm{kg})\end{array}$ & $34.2 \pm 10.8$ & $17.1 \pm 5.7^{*}$ & $17.7 \pm 6.5^{*}$ \\
\hline Umbilical glucose uptake & $4.0 \pm 1.1$ & $3.2 \pm 0.9$ & $3.4 \pm 1.9$ \\
\hline $\begin{array}{l}\text { Lactate delivery to fetus } \\
(\mathrm{mg} / \mathrm{min} / \mathrm{kg})\end{array}$ & $31 \pm 10$ & $19 \pm 5 \dagger$ & $25 \pm 10$ \\
\hline Umbilical lactate uptake & $1.9 \pm 0.9$ & $1.4 \pm 0.6$ & $1.2 \pm 1.2$ \\
\hline
\end{tabular}

Table 2. Effect of acute cord compression on total umbilicalplacental delivery and umbilical uptake of oxygen, glucose, and lactate in eight fetal lambs

$* p<0.001$

$\dagger p<0.01$. 
compression; however, there was no significant change in fetal oxygen consumption. Oxygen concentrations fell in the DA but did not change in the UV, resulting in an increase in the difference between umbilical venous and descending aortic oxygen content from $3.6 \pm 0.5$ to $7.5 \pm 1.9 \mathrm{~mL} / \mathrm{dL}(p<0.001)$.

Glucose delivery from the umbilical-placental circulation fell by approximately one-half from $34 \pm 11$ to $17 \pm 6 \mathrm{mg} / \mathrm{min} /$ $100 \mathrm{~g}$. There was a trend towards a reduction in the glucose concentration in the descending aorta and an increase in umbilical venous glucose concentrations such that the difference in umbilical venous and descending aortic glucose concentrations increased from $1.9 \pm 0.7$ to $4.7 \pm 2.6 \mathrm{mg} / \mathrm{dL}(p<0.01)$. Umbilical glucose uptake was not significantly reduced. Umbilical-placental lactate delivery to the fetus decreased after cord compression $(p<0.01)$, and then tended to increase as umbilical venous lactate concentrations increased. There was no significant change in the umbilical uptake of lactate. Reductions in oxygen, glucose, and lactate delivery to the fetus were proportional to the changes in umbilical blood flow $(r=0.79, p<0.0001$ for oxygen; $r=0.78, p<0.0001$ for glucose; $r=0.61, p<0.0005$ for lactate).

The effect of acute umbilical cord compression on delivery and utilization of oxygen, glucose, and lactate by the fetal liver is summarized in Table 3. Umbilical venous concentrations of oxygen and glucose were unchanged after acute cord compression (Table 1). As the umbilical vein supplies all of the blood to the $\mathrm{LL}$ and most of the blood to the RL, total oxygen, glucose, and lactate delivery to the liver decreased proportionately with reductions in hepatic blood flow (Fig. 1). After cord compression, there was a reduction of approximately $70 \%$ in total oxygen delivered to the fetal liver. Fetal liver $\mathrm{O}_{2}$ uptake did not change because the liver extracted a greater portion of the total oxygen received from umbilical venous and portal venous blood (Fig. 2 ). Thus, oxygen concentration in the hepatic vein decreased from $9.6 \pm 2.7$ to $7.9 \pm 2.3(p<0.05)$ after $15 \mathrm{~min}$ and to $6.0 \pm$ $1.8 \mathrm{~mL} / \mathrm{dL}(p<0.01)$ after $30 \mathrm{~min}$ of cord compression (Table $1)$.

As we have previously demonstrated (8), in the unstressed fetus there was no glucose consumption or production by the

Table 3. Effect of acute cord compression on hepatic uptake and extraction of oxygen, glucose, and lactate in eight fetal lambs*

\begin{tabular}{lccc}
\hline & \multicolumn{3}{c}{ Cord compression } \\
\cline { 2 - 4 } & Control & $15 \mathrm{~min}$ & $30 \mathrm{~min}$ \\
\hline $\begin{array}{c}\text { Oxygen delivery to liver } \\
\text { (mL/min/100 g) }\end{array}$ & $37 \pm 11$ & $15 \pm 10 \dagger$ & $10 \pm 6 \dagger$ \\
$\begin{array}{l}\text { Hepatic oxygen uptake } \\
\text { Oxygen extraction (\%) }\end{array}$ & $\begin{array}{c}4.0 \pm 2.6 \\
10 \pm 7\end{array}$ & $3.6 \pm 1.1$ & $4.4 \pm 3.0$ \\
$\begin{array}{c}\text { Glucose delivery to liver } \\
\text { (mg/min/100 g) }\end{array}$ & $67 \pm 24$ & $30 \pm 14 \ddagger$ & $20 \pm 13 \dagger$ \\
$\begin{array}{c}\text { Hepatic glucose uptake } \\
\quad(\mathrm{mg} / \mathrm{min} / 100 \mathrm{~g})\end{array}$ & $0.1 \pm 2.4$ & $-3.1 \pm 2.5 \ddagger$ & $-3.9 \pm 7.3 \ddagger$ \\
$\begin{array}{c}\text { Hepatic glucose uptake } \\
\quad(\mathrm{mg} / \mathrm{min} / \mathrm{kg})\end{array}$ & $0.1 \pm 0.8$ & $-1.2 \pm 0.8 \S$ & $-1.5 \pm 2.8$ \\
$\begin{array}{c}\text { Lactate delivery to liver } \\
\quad(\mathrm{mg} / \mathrm{min} / 100 \mathrm{~g})\end{array}$ & $62 \pm 20$ & $36 \pm 18.5 \dagger$ & $31 \pm 23 \dagger$ \\
$\begin{array}{c}\text { Hepatic lactate uptake } \\
\quad(\mathrm{mg} / \mathrm{min} / 100 \mathrm{~g})\end{array}$ & $3.3 \pm 1.7$ & $1.8 \pm 2.0$ & $1.4 \pm 0.9 \S$ \\
$\begin{array}{c}\text { Hepatic lactate uptake } \\
(\mathrm{mg} / \mathrm{min} / \mathrm{kg})\end{array}$ & $1.1 \pm 0.5$ & $0.6 \pm 0.6$ & $0.4 \pm 0.3 \S$ \\
$\begin{array}{c}\text { Glucose derived from lactate } \\
\text { (mg/min/100 g) }\end{array}$ & $0.09 \pm 0.14$ & $0.02 \pm 0.06$ & $0.23 \pm 0.55$ \\
\hline
\end{tabular}

* Total hepatic glucose or lactate uptakes $(\mathrm{mg} / \mathrm{min} / \mathrm{kg})$ were calculated by multiplying the measured uptake by the $\operatorname{LL}(n=6)$ or RL $(n=2)$ $(\mathrm{mg} / \mathrm{min} / \mathrm{g})$ by the total liver $(\mathrm{g})$. Negative numbers indicate net release of substrate from liver.

$$
\begin{aligned}
& \dagger p<0.001 \\
& \ddagger p<0.01 . \\
& \S p<0.05 .
\end{aligned}
$$
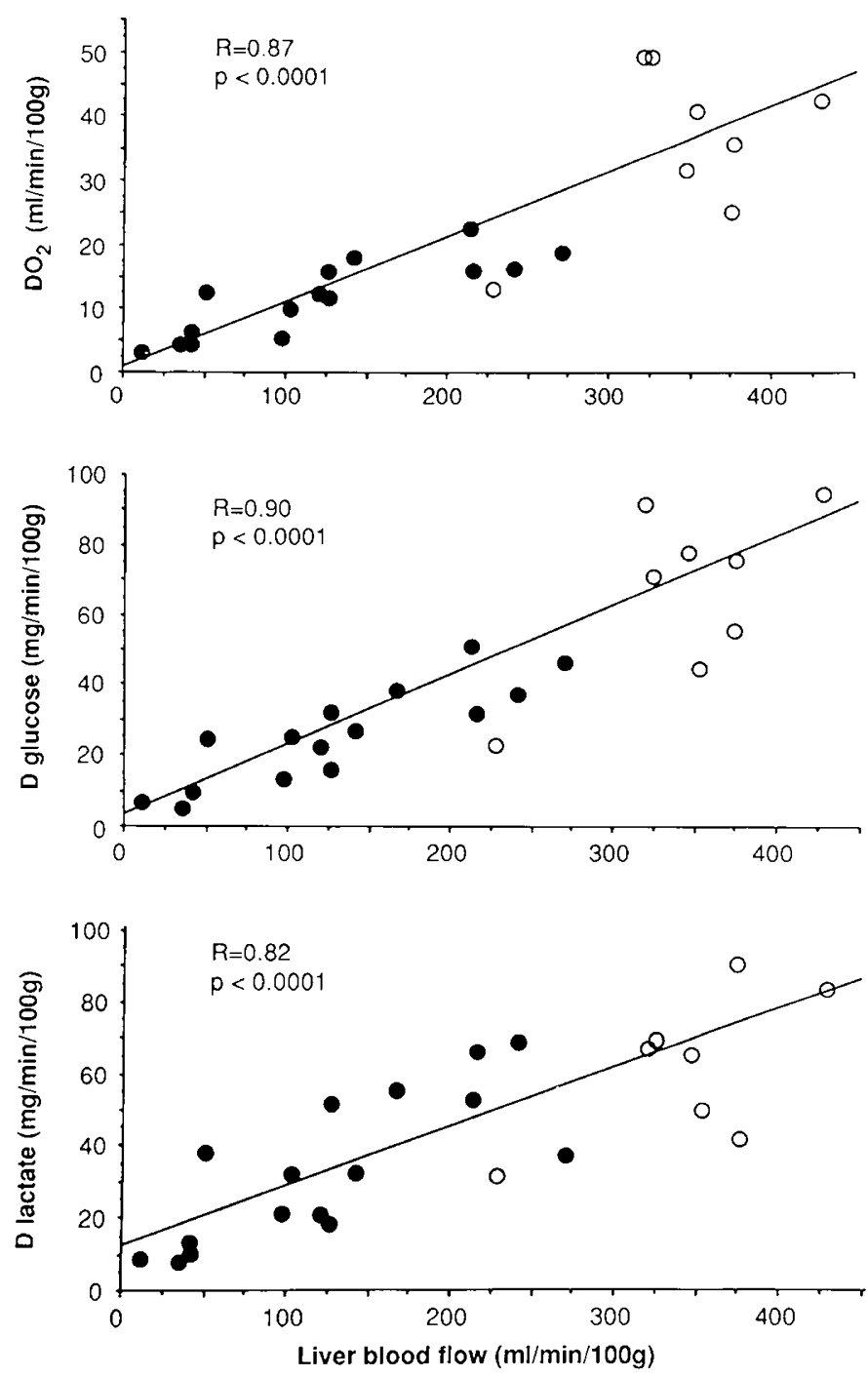

Fig. 1. Changes in the delivery (D) of oxygen, glucose, and lactate to the liver as a function of liver blood flow $(\dot{\mathrm{Q}}) . \mathrm{O}=$ control, $\boldsymbol{O}=$ umbilical cord compression. The regression line includes all data shown.

fetal liver. Glucose concentrations in the hepatic vein increased from $18 \pm 5$ to $23 \pm 6 \mathrm{mg} / \mathrm{dL}(p<0.01)$ and fetal hepatic glucose output increased from $-0.1 \pm 2.4$ to $3.9 \pm 7.3 \mathrm{mg} / \mathrm{min} / 100 \mathrm{~g}(p$ $<0.05)$ after $30 \mathrm{~min}$ of cord compression. There was no significant hepatic production of ${ }^{14} \mathrm{C}$-glucose from ${ }^{14} \mathrm{C}$-lactate. Despite the large reductions in hepatic blood flow, lactate delivery to the fetal liver decreased to only $40 \%$ of control because umbilical venous lactate concentrations increased. Liver lactate consumption varied linearly with the delivery of lactate (Fig. 3) such that $5.6 \pm 2.2 \%$ of delivery lactate was utilized by the liver, regardless of delivery rate.

\section{DISCUSSION}

We examined the effect of acute umbilical cord compression on umbilical and hepatic uptake of oxygen, glucose, and lactate. We demonstrated previously (1) that reducing umbilical blood flow by $50 \%$ for $5 \mathrm{~min}$ results in marked alterations in the distribution of umbilical venous blood returning from the placenta with an increased percentage of umbilical venous return being shunted away from the liver through the ductus venosus. This resulted in more than $60 \%$ reductions in hepatic blood flow, whereas flow to other organs was either increased or maintained. The present results demonstrate that the redistribution of 


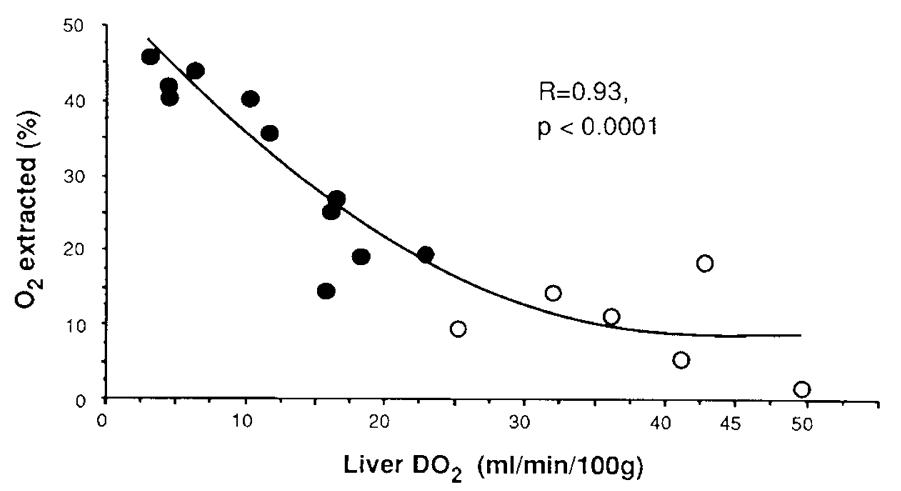

Fig. 2. Changes in the precentage of $\mathrm{O}_{2}$ extracted $\left(\mathrm{O}_{2}\right.$ delivered to liver $-\mathrm{O}_{2}$ leaving liver $/ \mathrm{O}_{2}$ delivered to liver) as a function of $\mathrm{O}_{2}$ delivery to the liver. $\mathrm{O}=\mathrm{Control}, \boldsymbol{=}=$ umbilical cord compression. The regression line includes all data shown.

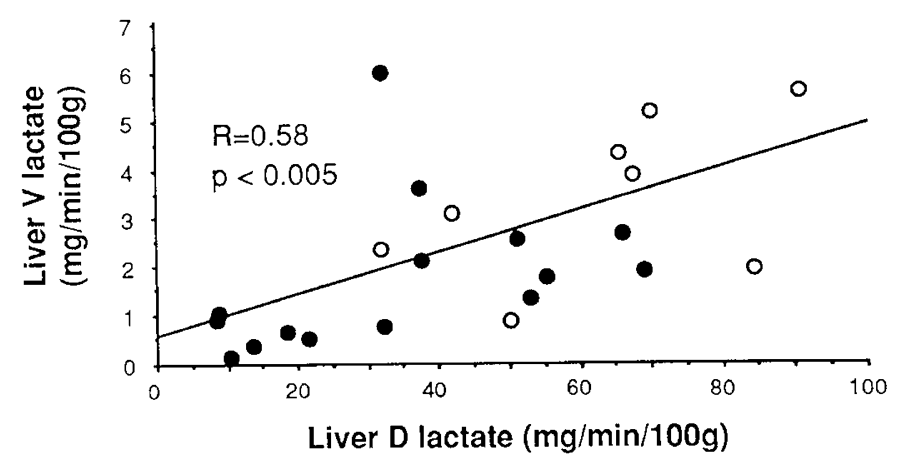

Fig. 3. Liver lactate uptake compared with delivery of lactate. $\bigcirc=$ control, $\bullet=$ umbilical cord compression. The regression line includes all data shown.

umbilical venous return persisted for at least $30 \mathrm{~min}$ of cord compression, but liver blood flow decreased further, to $75 \%$ of control values. After 5 min of cord compression, lower carcass flow increased; however, by 15 and $30 \mathrm{~min}$, lower carcass flow decreased, with other lower body flow measurements being unchanged.

Acute cord compression decreased oxygen delivery to the liver by $75 \%$. Hepatic oxygen consumption did not change due to a compensatory increase in the amount of oxygen extracted by the liver. In contrast, after maternal hypoxia, hepatic oxygen delivery decreased by only $40 \%$, but as oxygen delivery decreased, there was a proportional decrease in oxygen consumption (8). These contrasting results indicate that the total amount of oxygen delivered to the liver is not the only factor affecting liver oxygen consumption. Hepatic extraction of oxygen from blood requires the maintenance of a blood to tissue $\mathrm{O}_{2}$ diffusion gradient. We have not measured the $\mathrm{P}_{\mathrm{O}_{2}}$ of hepatic venous blood after cord compression or hypoxemia; however, $\mathrm{Hb}$ saturation decreased to $45 \%$ after cord compression and to $25 \%$ after hypoxemia, corresponding to reductions of $\mathrm{P}_{\mathrm{O}_{2}}$ to approximately 17 torr and 14 torr, respectively. $\mathrm{DA} \mathrm{P}_{\mathrm{O}_{2}}$ decreased to 15 torr after cord compression versus 11 torr after hypoxemia. The magnitude of the blood to tisue $\mathrm{O}_{2}$ gradient may be reduced more by hypoxemia than by cord compression, thereby limiting hepatic oxygen consumption. Cord compression also results in an increase in blood $\mathrm{P}_{\mathrm{CO}_{2}}$ and a decrease in $\mathrm{pH}$, shifting the $\mathrm{Hb}$ oxygen dissociation curve to the right, further improving the availability of oxygen to hepatocytes. During the hypoxemia studies of fetal hepatic $\mathrm{O}_{2}$ uptake, blood $\mathrm{pH}$ and $\mathrm{P}_{\mathrm{CO}_{2}}$ did not change (8).

We have previously demonstrated that there is no glucose uptake or production by the fetal liver in the unstressed fetus ( 8 , 17). Hypoxemia stimulated heptic production of $6-9 \mathrm{mg} / \mathrm{min} /$ $100 \mathrm{~g}$ of glucose. Umbilical glucose uptake did not significantly change; therefore, during hypoxemia, the liver provided $45 \%$ of the total glucose available to the fetus (8). After acute cord compression, the magnitude of hepatic glucose production was somewhat smaller $(4 \mathrm{mg} / \mathrm{min} / 100 \mathrm{~g})$. Umbilical glucose uptake did not change. Thus, total glucose provided to the fetus from umbilical uptake and liver production increased from $4.0 \pm 1.1$ to $4.9 \pm 2.2 \mathrm{mg} / \mathrm{min} / \mathrm{kg}(p<0.05)$, with the liver contributing approximately $30 \%$. Despite this increase in total glucose supply, aortic concentrations of glucose were unchanged during acute hypoxemia or cord compression, suggesting that fetal glucose utilization increased. Reductions in oxygen delivery occur during both of these stresses. This may shift some tissues from aerobic to anaerobic metabolism, thereby increasing glucose utilization and lactate production. For example, during acute hypoxemia, fetal renal net glucose flux changes from glucose release to net glucose uptake, and lactate flux changes from net lactate uptake to net release (18).

Control hepatic lactate uptake was not significantly different in this study $(3.3 \pm 1.7 \mathrm{mg} / \mathrm{min} / 100 \mathrm{~g})$ than reported previously by this laboratory $(5.0 \pm 4.4)(7)$. Acute cord compression did not alter umbilical lactate uptake; however, blood lactate concentrations nearly doubled, indicating that either fetal lactate consumption decreased or production increased. To increase lactate concentrations over the $30 \mathrm{~min}$ period of occlusion by an estimated $0.3 \mathrm{mg} / \mathrm{dL} / \mathrm{min}$ would require net addition of $2.3 \mathrm{mg} /$ $\mathrm{min} / \mathrm{kg}$ to the body lactate pool using a vol of distribution for lactate of $650 \mathrm{~mL} / \mathrm{kg} \mathrm{(5).} \mathrm{Because} \mathrm{hepatic} \mathrm{lactate} \mathrm{uptake} \mathrm{de-}$ creased by only $0.7 \mathrm{mg} / \mathrm{min} / \mathrm{kg}$, alterations in hepatic lactate uptake clearly cannot fully explain the rise in blood lactate concentrations; changes in consumption by other lactate-utilizing organs (heart and kidney), or increased fetal lactate production must occur. As noted above, during cord compression there may be decreased aerobic utilization of glucose with increase lactate production. Hepatic lactate uptake decreased during cord compression. This could be explained simply by the decrease in lactate delivery as hepatic blood flow was reduced. However, the liver increased the percentage of delivered oxygen extracted and therefore maintained oxygen consumption during cord compression. An alternative substrate to lactate must be utilized by the liver to account for the hepatic oxygen consumption not changing.

The stimuli promoting glucose production by the fetal liver during acute cord compression or hypoxemia have not been determined. In adult mammals, hepatic glucose production is stimulated by reductions in blood glucose concentration or by a variety of stresses (19). Umbilical uptake of glucose and arterial blood glucose concentrations were unchanged during both acute cord compression and maternal hypoxemia. Delivery of glucose to the liver decreased after cord compression but not during maternal hypoxemia. Therefore, it is unlikely that changes in fetal glucose concentration or hepatic delivery play a major role in promoting hepatic glucose output.

Hormones, including glucagon, epinephrine, norepinephrine, and vasopressin, all may act as physiologic stimuli to hepatic glycogenolysis (19). Acute hypoxemia increases plasma concentrations of norepinephrine, epinephrine, and vasopressin (20), and also increases plasma glucagon concentrations (21) in fetal lambs. Acute cord compression similarly increases norepinephrine and epinephrine (22); however, changes in glucagon, vasopressin, and angiotensin II have not been studied. Determination of the specific role of each of these hormones as stimuli for fetal hepatic glucose release during hypoxemia or cord compression will require further study using specific antagonists.

In adult mammals, liver glycogenolysis is also very sensitive to reductions in oxygen tension in the liver (19); as oxygen supply decreases, glycogenolysis is accelerated due to an increase in phosphorylase "a" activity (23). Oxygen delivery to the liver decreases dramatically during acute cord compression and during hypoxemia. As noted above, the magnitude to measured hepatic glucose output was somewhat greater during hypoxemia versus 
cord compression. Interestingly, the hepatic venous $\mathrm{P}_{\mathrm{O}_{2}}$ was lower during hypoxemia. Possibly, these reductions in oxygen tension in the liver increase glucose production by the liver, independent of neural or hormonal stimuli.

This study confirms our previous results demonstrating that in the unstressed fetus, there is no substantial hepatic gluconeogenesis from lactate (17). As there is no net glucose production by the liver, this is not surprising. However, even after fetal hepatic glucose production was stimulated during acute cord compression, there was no detectable hepatic gluconeogenesis. We cannot exclude the possibility that there is a small amount of hepatic gluconeogenesis from lactate, but it certainly does not account for a large portion of the glucose output from the liver. In the fetal lamb, the enzymes required for gluconeogenesis are present by $120 \mathrm{~d}$ of gestation (24). Therefore, the lack of gluconeogenesis requires an alternate explanation. Duée et al. (25) studied hepatocytes from term fetal and newborn rabbits (25). They observed that the onset of significant gluconeogenesis from lactate occurs only after hepatic glycogen stores are depleted. At $122 \mathrm{~d}$ of gestation, the fetal lamb liver contains approximately $20 \mathrm{mg}$ glycogen $/ \mathrm{g}$ wet wt (3). Assuming that the rate of liver glucose production from glycogen during cord compression was $4 \mathrm{mg} / \mathrm{min} / 100 \mathrm{~g}$, there would be only a $6 \%$ reduction in hepatic glycogen content after $30 \mathrm{~min}$ of cord compression. It is reasonable to expect that hepatic gluconeogenesis from lactate will occur only after a more prolonged stress, which depletes glycogen stores. Fetal gluconeogenesis has been demonstrated during the chronic stress of maternal starvation (4). Perhaps chronic cord compression or hypoxemia would have a similar effect.

Acknowledgements. The authors thank Mr. Carl McWatters and Mr. Bruce Payne for their help with the microsphere data analysis and Mr. Paul Sagan for preparing and editing this manuscript.

\section{REFERENCES}

1. Itskovitz J, LaGamma EF, Rudolph AM 1987 Effects of cord compression on fetal blood flow distribution and $\mathrm{O}_{2}$ delivery. Am J Physiol 252:H100-H109

2. Battaglia FC. Meschia G 1978 Principal substrates of fetal metabolism. Physiol Rev 58:499-527

3. Barnes RJ, Comline RS, Silver M 1978 Effect of cortisol on liver glycogen concentrations in hypohysectomized, adrenalectomized and normal foetal lambs during late or prolonged gestation. J Physiol (Lond) 275:567-579

4. Hay WW Jr, Sparks JW, Quissell BJ, Battaglia FC, Meschia G 1981 Simultaneous measurements of umbilical uptake, fetal utilization rate, and fetal turnover rate of glucose. Am J Physiol 240:E662-E668

5. Warnes DM, Seamark RF, Ballard FJ 1977 The appearance of gluconeogenesis at birth in sheep: activation of the pathway associated with blood oxygenation. Biochem J 162:627-634

6. Gleason CA, Rudolph AM 1986 Oxygenation does not stimulate hepatic gluconeogenesis in fetal lambs. Pediatr Res 20:532-535

7. Gleason CA, Rudolph CD, Bristow J, Rudolph AM 1985 Lactate uptake by the fetal sheep liver. J Dev Physiol 7:177-183

8. Bristow J, Rudolph AM, Itskovitz J. Barnes RJ 1983 Hepatic oxygen and glucose metabolism in the fetal lamb: response to hypoxia. J Clin Invest 71:1047-1061

9. Bristow J, Rudolph AM, Itskovitz J 1981 A preparation for studying liver blood flow, oxygen consumption, and metabolism in the fetal lamb in utero. J Dev Physiol 3:255-266

10. Itskovitz J, LaGamma EF, Rudolph AM 1983 The effects of reducing umbilical blood flow on fetal oxygenation. Am J Obstet Gynecol 145:813-818

11. Rognstad R, Katz J 1977 Role of pyruvate kinase in the regulation of gluconeogenesis from L-lactate. J Biol Chem 252:1831-1833

12. Sparks JW, Hay WW, Bonds D, Meschia G, Battaglia FC 1982 Simultaneous measurements of lactate turnover rate and umbilical lactate uptake in the fetal lamb. J Clin Invest 70:179-192

13. Heymann, MA, Payne BD, Hoffman HIE, Rudolph AM 1977 Blood flow measurements with radionuclide-labeled particles. Prog Cardiovasc Dis 20: 55-79

14. Edelstone DI. Rudolph AM, Heymann MA 1978 Liver and ductus venosus blood flows in fetal lambs in utero. Circ Res 42:426-433

15. Chiasson JL, Liljenquist JE, Sinclair-Smith BC, Lacy WW 1975 Gluconeogenesis from alanine in normal postabsorptive man: intrahepatic stimulatory effect of glucagon. Diabetes 24:574-584

16. Itskovitz J, LaGamma EF, Rudolph AM 1983 Heart ratc and blood pressure responses to umbilical cord compression in fetal lambs with special reference to the mechanism of variable deceleration. Am J Obstet Gynecol 147:451 457

17. Gleason CA, Rudolph AM 1985 Gluconeogenesis by the fetal sheep liver in vivo. J Dev Physiol 7:185-194

18. Iwamoto HS, Rudolph AM 1985 Metabolic responses of the kidney in fetal sheep. Effect of acute and spontaneous hypoxemia. Am J Physiol 249:F836F841

19. Hems DA, Whitton PD 1980 Control of hepatic glycogenolysis. Physiol Rev $60: 1-50$

20. Robillard JE, Weitzman RE, Burmeister L, Smith FG 1981 Developmental aspects of the renal response to hypoxemia in the lamb fetus. Circ Res 48:128-138

21. Shelley HJ, Girard JR 1981 Plasma insulin and glucagon in well oxygenated and hypoxic fetal lambs. In: DeMeyer $R$ (ed) Metabolic Adaptation to Extrauterine Life. Nijhoff, The Hague, pp 261-279

22. Lewis AB, Wolf WJ, Sischo W 1984 Cardiovascular and catecholamine responses to successive episodes of hypoxemia in the fetus. Biol Neonate 45:105-111

23. Sharma RJ, Rodrigues LM, Hems DA 1978 Activation of hepatic glycogen phosphorylase in anoxic liver. Biochem Soc Trans 6:1319-1321

24. Ballard FJ, Oliver IT 1965 Carbohydrate metabolism in liver from fetal and neonatal sheep. Biochem J 95:191-200

25. Duée PH, Pégorier JP, el Manoubi L, Ferré P, Bois-Joyeux B, Girard J 1986 Development of gluconeogenesis from different substrates in newborn rabbit hepatocytes. J Dev Physiol 8:387-394 